\title{
MODELING TRAUMATIC BRAIN INJURY: MECHANISMS OF EARLY NEURONAL AND AXON DEGENERATION IN THE INFANT RODENT BRAIN
}

\author{
Krikor Dikranian \\ Department of Neuroscience, Washington University School of Medicine, Saint Louis, MO,USA
}

Traumatic brain injury (TBI) remains a major health challenge and affects the young disproportionately. Accidental and nonaccidental TBI in children is a major contributor to morbidity, disability, and death. TBI in this critical period leads to profound neuronal and axonal degeneration followed by cognitive, psychological and memory impairment, altered processing speed, impaired executive functions, emotional liability as well as word finding difficulties. Cognitive and behavioral changes may remain unrecognized for periods even after sustaining mild injury. Although accidental and non-accidental inflicted injury (blunt force or violent shaking-inflicting brain injury or "Shaken baby" syndrome) posits a major clinical and sociological problem, mechanisms of tissue degeneration might be largely similar. The scope of this review will be the experimental research related to modeling blunt (concussive) head trauma specifically to the infant rodent brain resulting in acute (early) and protracted (late) degenerative changes such as axonal degeneration and apoptotic neuronal cell death. Similarly, discussion will be limited to therapeutic windows and potentials for ameliorating the development of early brain injury. Biomed Rev 2019;30:25-36

Key words: traumatic brain injury, excitotoxic cell death, apoptotic cell death, axonal injury

\section{INTRODUCTION}

While accidental TBI has been recognized for hundreds of years, the history of reporting non-accidental brain trauma begins in 1860 by the publication of an article by the French physician, Ambroise Tardieu, describing 32 cases of physical abuse (61). Later, in 1946 John Caffey reported cases with subdural hematomas in six children (61). Finally, many years later, a publication in 1962 named "The battered child syndrome" made history by leading to the creation of laws protecting children in the USA including the reporting of child maltreatment (45). Importantly, following legislations have also sparked the interest and attention of the medical and academic communities in studying the pathophysiological mechanisms of all TBIs as well as their diagnosis and treatment options. More than half a million children (around 600000 as reported in 2012) sustain TBI and are hospitalized in the USA alone. Of these 300000 are from contact sports alone. More than 50000 of hospitalizations end up with disabilities,

Received 19 November 2019, revised 2 December 2019, accepted 8 December 2019.

Correspondence to: Krikor Dikranian, MD, PhD, Department of Neuroscience, Washington University School of Medicine, 660 S. Euclid Ave, Saint Louis, MO 63110, USA

Email: dikranik@wustl.edu 
of them about $10 \%$ need intensive inpatient care and rehabilitation. Annually there are 7400 deaths with fatality rate between $30.5 \%$ and $35.7 \%(3,74)$. Children under six years of age sustain traumatic brain injury more frequently than any other age group $(2,3)$. From all pediatric head trauma hospitalizations, $11.6 \%$ were infants below the age of 1 year. According to the recent literature there are two large peaks in pediatric TBI and the first one is in early childhood -0 to 4 years (74). The infant is highly susceptible to head trauma and brain injury is the most important outcome of head contusion (3, 25, 30, 31, 32, 35, 57). A study in 1995 has found that in a cohort of children suffering severe head injury prior to the age of 4 years none was able to work independently outside a structured environment years later, whereas children older than 4 years at the time of injury had a better outcome $(48,74,75)$. Recent developments in clinical trials for the treatment of TBI lead to the following conclusions: in many cases "mild" brain injury is never really mild, functional deficits may appear long after the initial injury and post-injury structural and functional reorganization may not always be adaptive. Importantly no neuroprotective agents are clinically available. The search for safe and effective therapy especially for the acute phase of TBI so far has been disappointing $(74,78)$.

\section{CRITICAL PERIODS OF BRAIN DEVELOPMENT}

During human brain development there are periods of time-sensitive sequential events that are critical to normal brain function in adult life. According to most studies, the neurogenesis and migration of neuroblasts starts at the embryonal age of 6 weeks, the incidences of programmed cell death starts at embryonal age of 24 months, while gliogenesis continues well after birth and in some cases around the postnatal age of 24 (71). Importantly, during the last trimester of fetal life and the first 2 years of childhood, the human brain undergoes a period of rapid growth termed the "brain growth spurt” (10, 39, 47, 54). It is characterized by a number of neurodevelopmental changes, including pronounced dendritic and axonal outgrowth, establishment of neural connections and circuits via intense synaptogenesis paralleled by synapse elimination $(22,23,49,71)$. In the rodent the "brain growth spurt" is shifted postnatally into the first two weeks of life $(5,8,34,81)$.

\section{MODELS OF TBI}

Several well established impact models are historically used to study TBI-induced neurodegeneration in immature (P3 and P21) rodents $(1,6,11,13,14,15,20,40,42,63,65)$. They correspond to infant and toddler age in humans $(66,82)$. Among these trauma models, three have been most widely used: the weight drop model $(30,41)$, the fluid percussion model (54) and the controlled cortical impact model $(21,40)$ The fluid percussion model produces brain injury by rapid injection of small volumes of saline into a closed cranial cavity against the dura mater $(2,63)$. The weight drop model was modified by Marmarou et al. (1994) to a closed head injury model (55). Our group used initially the weight drop model in an attempt to model infant TBI (41). To further study developmental TBI more precisely, a novel impact system was developed in 2006 at Washington University in Saint Louis to deliver a controlled impact to the flexible skull of an infant rodent ( 7 - 10 days postnatally). This system uses an electromagnetic actuator mounted on a stereotaxic instrument (Fig. 1) to impact the exposed skull at a specified angle, velocity and depth $(6,7,20)$. The device was intended to produce injury similar to that achieved with a weight-drop device $(12,41)$ but with improved precision and flexibility. With this device it was possible to consistently deliver impacts of comparable depth and injury characteristics, and at the same time determine whether the impact and injury was mild, moderate or severe depending on physiological manifestation, skull fracture, hemorrhage an tissue changes. Using similar device it was also possible to study mechanical strain associated with the impact. This method calculates maximum principal strain using tagged magnetic resonance imaging (MRI) of the brain during indentation of the skull and provides both qualitative and quantitative assessment of the mechanical insult to the tissue $(6,7)$. All traumatic brain injury models cause a rapid deformation of the cortical surface. This component of the tissue reaction entails direct tensile injury to nerve cell bodies and their white matter axons and appears to be the way developing nerve cell bodies and axons respond to rapid deformation. Any fiber tract passing through a portion of the impact zone where strains are high will be subjected to stretch injury $(6,7)$.

\section{EFFECT OF TBI ON THE INFANT BRAIN: EARLY EXCITOTOXIC NEURONAL CELL DEGENERATION.}

TBI to P3-P14 rodents has resulted in neuronal cell death which peaked relatively early, 24 hours post-injury. The initial trauma-induced cell degeneration is excitotoxic in nature (78) and occurs under the area of impact (a.k.a. penumbra area) (Fig. 2). This component of tissue reaction entails direct 

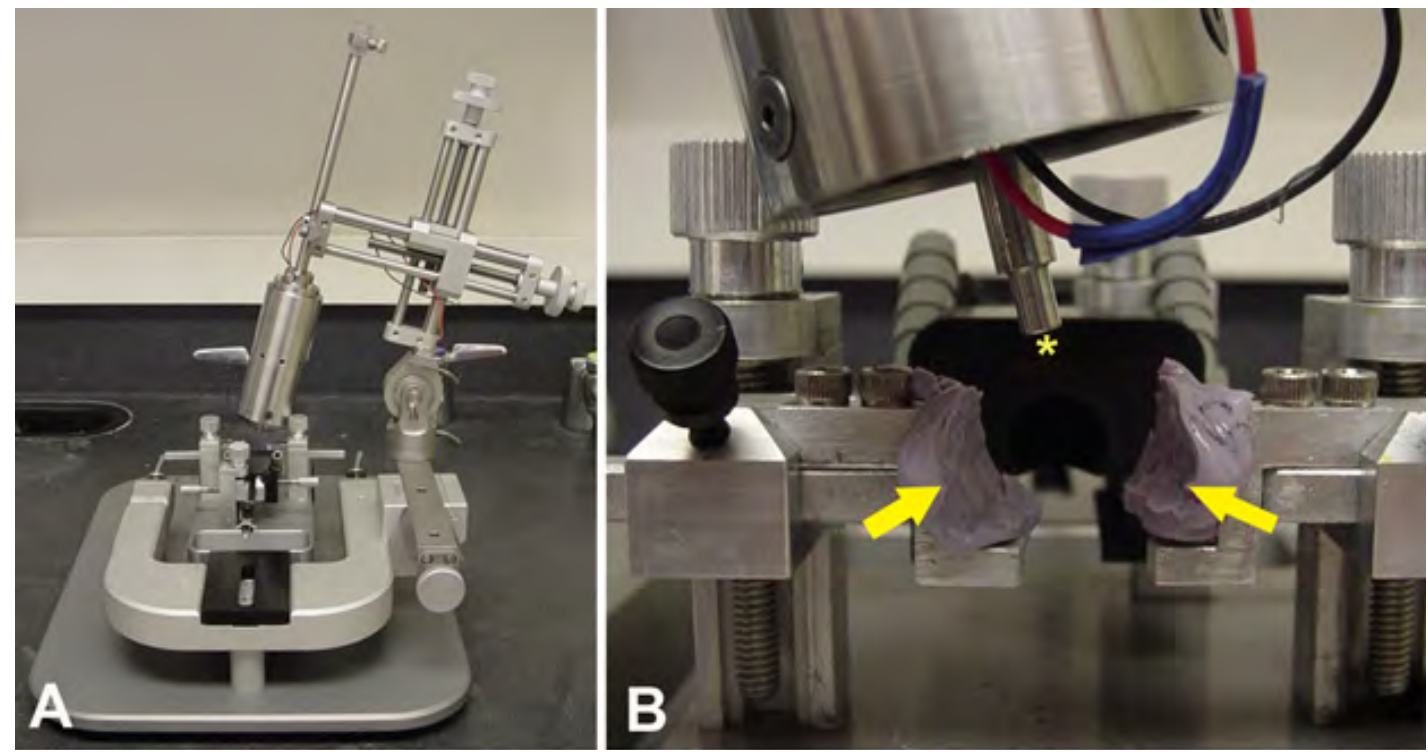

Figure 1. A. Image of the stereotaxic instrument with the electromagnetic actuator. B. Close up image showing the metal tip of the impactor (*) and the plastic molded head side support device (arrows).
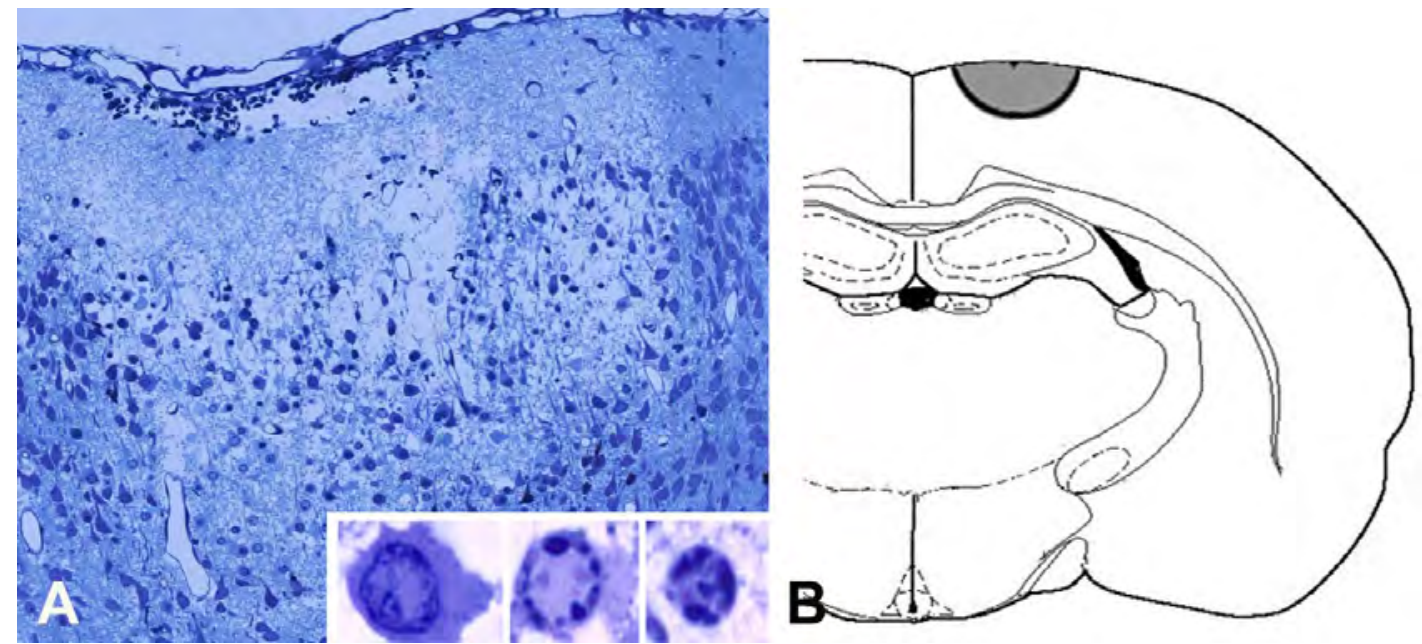

Figure 2. Penumbra area, plastic section (A) and diagram (B). Inset in A the shows development of excitotoxic neuronal changes (from left to right - one normal and two degenerating neurons).

tensile injury to nerve cell bodies and their axons and appears to be the way developing nerve cell bodies respond to rapid deformation. This is accompanied by early (within $30 \mathrm{~min}$ ) axonal swellings detected in the cingulum and external capsule, two white matter brain structures which sustain rapid tensile forces during impact $(6,7)$. The excitotoxic reaction kills affected neurons very rapidly - within 2 hours post impact. $(6,11,12,13,24,20,29)$. This type of cell degeneration has distinct features which were best evaluated by reviewing 1 $\mathrm{mm}$ plastic sections stained with toluidine blue and further examined with electron microscopy - the gold standard for evaluating excitotoxicity (42). Initially, neuronal cell bodies undergo extreme edematous swelling which is accompanied by degeneration of mitochondria. Specific nuclear changes begin by the formation of small aggregates of clumped chromatin which give the nucleus a floccular appearance (Fig. 2). These small clumps migrate to the perimeter of the nucleus in a clock-face pattern, then coalesce into progressively larger clumps and dense mass at the center of the nucleus. The nuclear membrane remains relatively intact but the plasma 
membrane becomes ruptured and loses its integrity early in the degenerative process. The release and accumulation of potentially damaging factors in the penumbra, such as calcium, excitatory amino acids neurotransmitters such as glutamate with subsequent activation of their specific receptors, are considered to be initiators of this type of damage $(11,27)$. Interestingly, after mild trauma to the P7 mouse we did not observe any ultrastructural morphological features consistent with excitotoxic cell degeneration in the early post-trauma period. Instead, we detected the first signs of apoptotic cell death. Clinically, excitotoxicity also plays a significant role in the pathogenesis of TBI in the neonate (71). In adult animal TBI studies mild trauma to the exposed skull has not produced similar effects (9) which suggest that excitotoxic injury can be unique mechanism of early cell degeneration in the infant brain.

\section{EFFECT OF TBI ON THE INFANT BRAIN: EARLY AXONAL DEGENERATION AND DISRUPTION}

The other component to the acute brain tissue reaction is the axonal fiber tract component - the underlying white matter. Previous studies have shown that TBI in the infant and toddler rodents causes axonal degeneration during the first week postinjury $(3,40)$. Early axonal injury to axons in the cingulum, external capsule, corpus callosum has been detected as early as 6 hours post trauma (67). However, the very early onset and progression of axonal injury (earlier that 4 hours post injury) has not been followed until 2008. In our mouse study we used a progeny of mThy1-YFP16 line overexpressing yellow fluorescent protein in neurons and axons (28) which in our hands became an excellent tool to evaluate temporal and morphological changes as well as the topography and spread of tissue injury (Fig. 3, 4, 5) even without the application of specific immunostaining methods used for revealing axonal injury such as APP expression (20, 24, 32, 33, 40). Our analysis of YFP-expressing transgenic mice showed that the cingulum bundle, corpus callosum external and internal capsule are the most vulnerable white matter tracts under conditions of mild to moderate/severe head trauma (Fig. 3). Importantly, our detailed structural and morphometric study of degenerating axonal profiles in the cingulum/external capsule also revealed that axonal injury, even after a mild insult, occurs surprisingly early (20) within 30 min post impact and progresses rapidly within 5 to 24 hours post trauma (Fig. 4). Injured axons undergo rapid and progressive morphological alterations. Initially seen as punctate spots in YFP-only (non-stained) and in APP immunolabeled sections (Fig 4A, C, and D), YFP positive and APP positive segments along each axonal axis became longer and thicker within 5 hours post-injury, and ended in larger spheroids or clubs-like swellings by 16 hours post
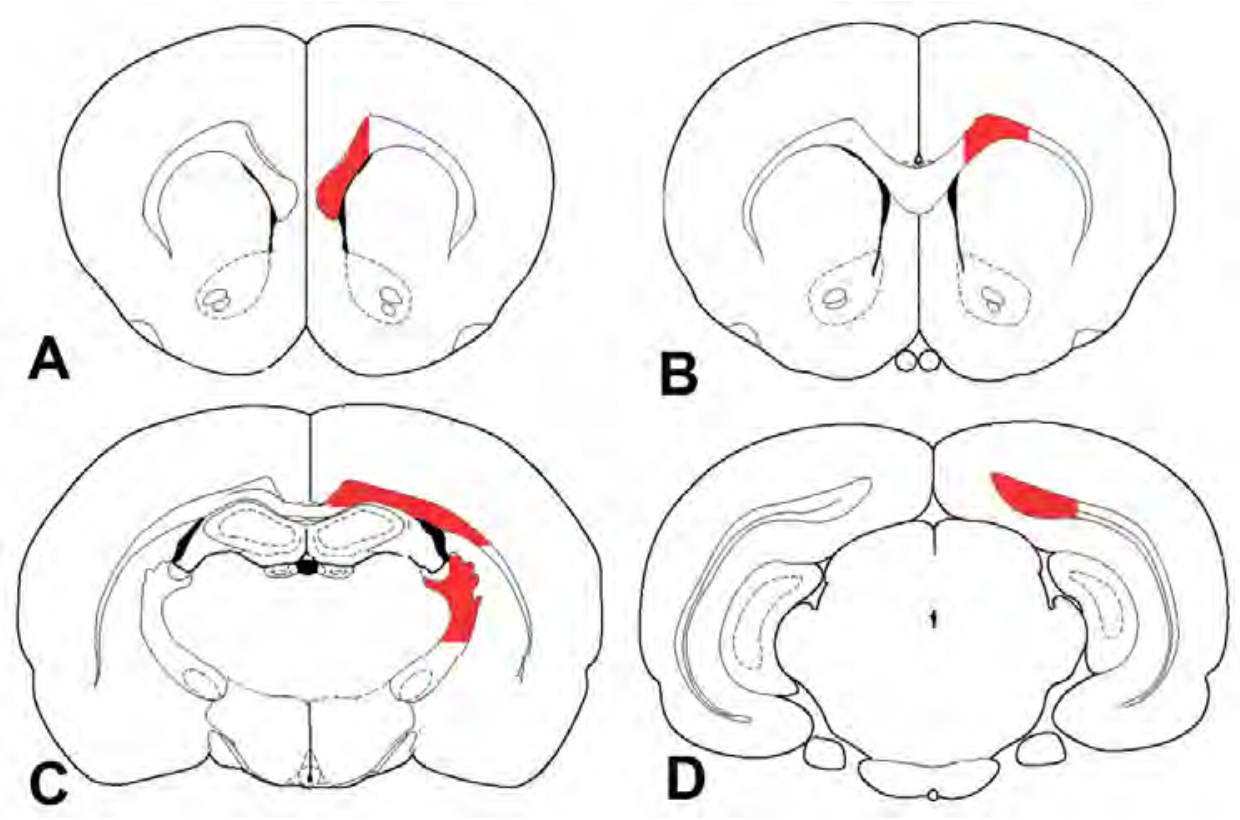

Figure 3. A- C - mouse cranio-caudal brain levels at which white matter axonal degeneration has been observed after mild to moderate/severe brain injury following skull impact. 

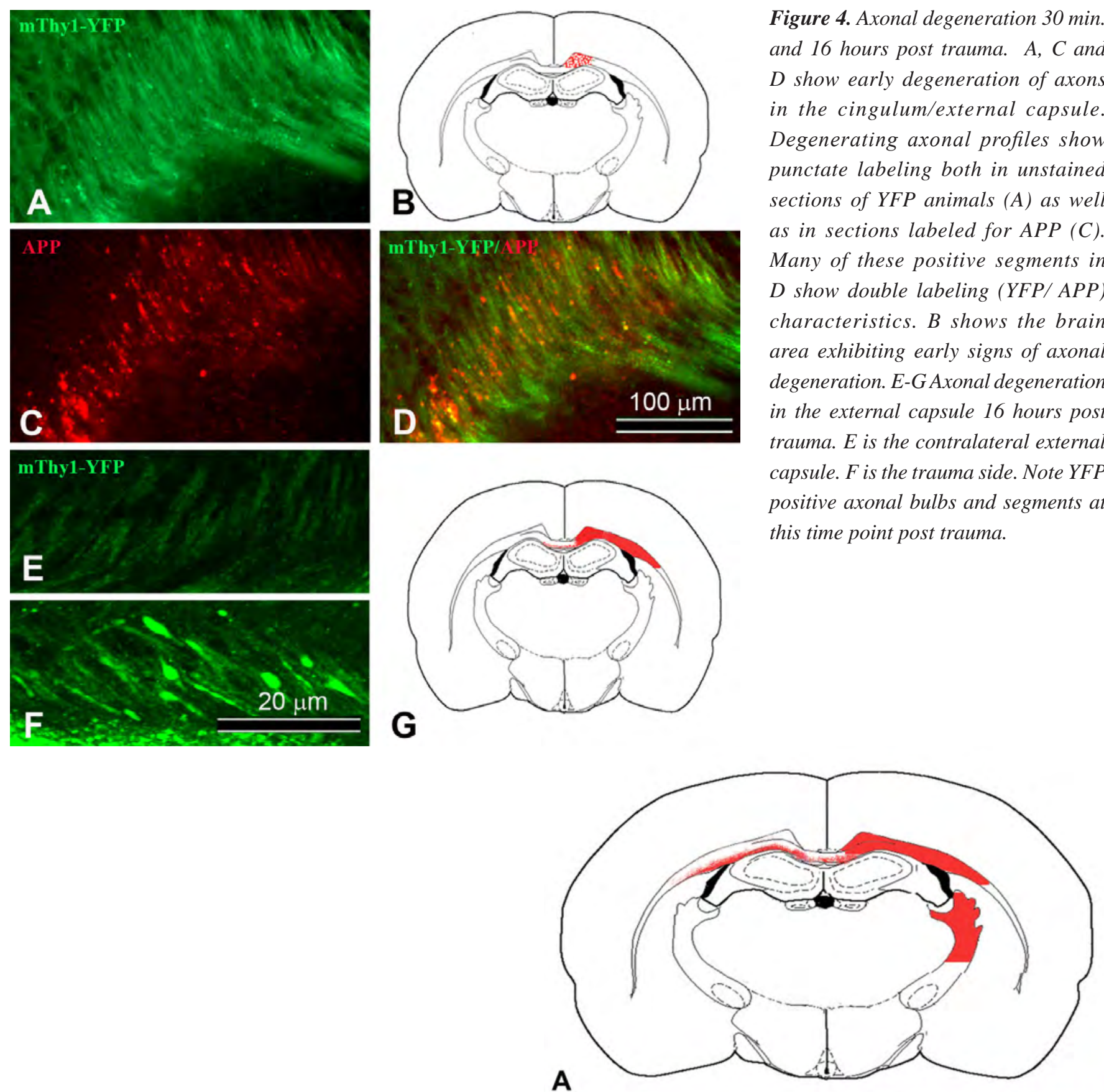

Figure 5. Axonal degeneration 15 hous after moderatel severe trauma. Diagram in A shows the areas of axonal degeneration. B and C (YFP only) show axonal degeneration in the ipsilateral (C) as well as in the contralateral external capsule (B). $G$ and $H$ - internal capsule, degenerating axons observed as spheroids only in the trauma side (E).
Figure 4. Axonal degeneration $30 \mathrm{~min}$. and 16 hours post trauma. A, C and $D$ show early degeneration of axons in the cingulum/external capsule. Degenerating axonal profiles show punctate labeling both in unstained sections of YFP animals (A) as well as in sections labeled for APP (C). Many of these positive segments in $D$ show double labeling (YFP/ APP) characteristics. B shows the brain area exhibiting early signs of axonal degeneration. E-GAxonal degeneration in the external capsule 16 hours post trauma. $E$ is the contralateral external capsule. $F$ is the trauma side. Note YFP positive axonal bulbs and segments at this time point post trauma.
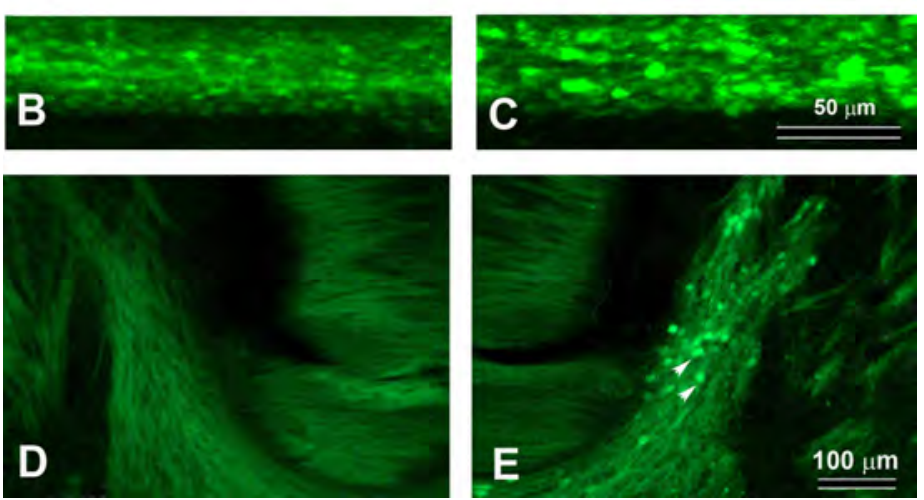
trauma (Fig. 4F) (20). Moderate to heavy trauma expanded the territory of axonal degenerations involving contralateral and deeper ipsilateral white matter tracts such as the contraleteral external capsule and the ipsilateral internal capsule (Fig. 5). Our electron microscopic studies showed axoplasmic organelle compaction in the spheroids suggesting that axonal transport might be impaired in these segments $(6,20)$. Similar studies implicating axonal disruption were made in adult animals (26, 44) and were associated with axonal disconnection.

Axonal fibers tracts in the underlying white matter in neonatal animals are fragile, they course and anchor at certain points, which determines how far they can stretch without tearing or exceeding injury thresholds. It is important also to consider that the axons in these white matter tracts in the immature rodents are still unmyelinated and can be more susceptible to mechanical strain and injury (68). A substantial mechanical strain and rapid tissue deformation is experienced by these tracts even after mild impact $(6,7,20)$. Computational studies have shown that for identical cortical displacement, the neonatal brain may be under larger peak stress magnitude compared to the mature brain due to smaller size and stiffer tissue properties (50). The fact that the internal capsule shows marked degeneration in axons, which is not seen after mild trauma, signifies that more severe trauma causes higher white matter stress upon impact.

\section{EFFECT OF TBI ON THE INFANT BRAIN: MASSIVE APOPTOTIC NEURONAL CELL DEATH}

Apoptotic cell death was highest in 3 and 7 day old rats and decreased significantly with increasing age. By the time excitotoxic neuronal degeneration has run its course within several hours post impact, apoptotic cell death in neurons takes over. Apoptosis is detectable over a longer time period, extending from 4 h to 48 hours post mild trauma (Fig. 6) (20) and up to 5 days after more severe TBI. Apoptotic cell death is disproportionally greater than excitotoxic neurodegeneration and displays a diffuse pattern affecting several brain regions $(6,10,11,12,13,20)$ depending on the severity of impact. The highest densities of apoptotic cells (mostly neurons) following trauma were detected in areas also displaying highest densities of physiologic or programmed death $(12,13,14)$. This may indicate that neurons (and possibly glia) may be most vulnerable to apoptosis when exposed to an exogenous insult during a certain vulnerable period of their maturation.
Figure 6. Apoptotic cell degeneration 15 hours post moderate trauma. A is a light microscopic image of Caspase 3 staining in the cingulate cortex and thalamus, $B$ is a fluorescent microscopy image in a YFP animal stained for Caspase 3. Apoptotic cell degeneration is seen in the superficial and deep layers of the cingulate cortex. $C$ shows the topography of Caspase 3 positive apoptotic cell death in the cortex, hippocampus, habenula and thalamus.
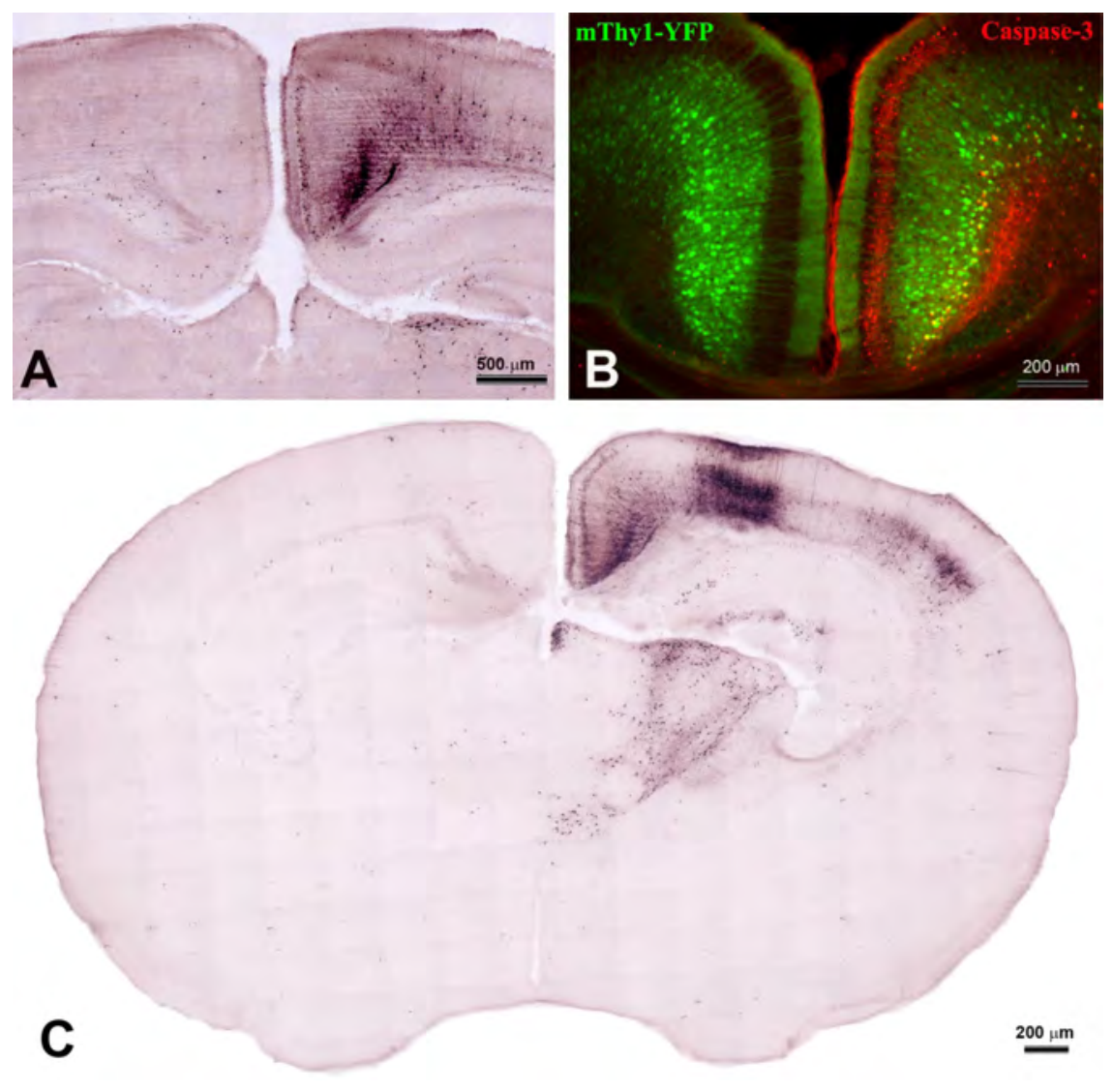
In the case of mild and moderate TBI the early apoptotic injury within the cingulate cortex was followed by apoptotic cell death affecting specifically the anterior thalamic nucleus which establishes bidirectional anatomic connections with the cingulate cortex and thalamocortical and corticothalamic projections pass through the cingulum/external capsule (62, 72). Various studies have shown that normal function and survival of neurons in the developing brain is also maintained via proper synaptic connection and activity, and in many instances by synaptic activity dependent trophic support between projecting neurons and target cells (16). Loss of synaptic connections in the developing brain can cause nerve cells to commit suicide. It is therefore possible that communications between these areas will be disrupted either by cell death and/ or axonal damage. Loss of synaptic connections between partnering neuronal groups may potentially trigger a second way of apoptosis at close and distant brain regions. For example experimental target deprivation (visual cortex ablation) in infant animals has resulted in neuronal apoptosis in the lateral geniculate nucleus (58). Potential involvement of disconnection mechanisms after TBI has been discussed also by others (18). It is possible, therefore, that during the synaptogenesis period, head trauma has the potential to enhance physiological cell suicide mechanisms in the brain in multiple ways and kill millions of neurons.

\section{POTENTIAL STRATEGIES FOR NEUROPROTECTION}

\section{Anti-excitotoxic therapies}

NMDA antagonists which block the effect of excitotoxicity such as ketamine have been used in clinical practice $(36,37)$. Experimental evidence from infant rodents has shown that while similar NMDA antagonists are capable of protecting early excitotoxic cell degeneration, they have caused an increase in apoptotic cell death (64) which renders this approach impractical in the current form. Further studies are needed to address pharmacological treatment of early post-traumatic excitotoxic neurodegeneration in infant models of TBI (see also Bittigau et al.,1998 for extensive discussion on potential protective strategies).

\section{Axonal injury and disconnection therapies}

Given the rapid development of axonal degeneration in the infant brain following mild TBI, two potential clinically relevant questions need to be asked. The first is, is there a non-invasive clinical diagnostic tool by which we can map the territory and extent of axonal injury? In the past decade diffusion tensor imaging (DTI) has emerged as a reliable tool to register axonal injury both in rodent models of TBI as well as in the clinic (51, 52,80 ). Results from the clinic suggest that DTI measures such as reduced anisotropy are sensitive but are discussed as longterm changes correlated to posttraumatic clinical evaluations in children (80). Our results in adult mice showed that both histological markers of TBI such as APP immunolabeling as well as certain DTI parameters (reduced axial diffusivity and relative anisotropy) were positively correlated in the extent of axonal injury in the pericontusion zone following moderate to severe trauma to the exposed skull. In an experimental TBI study of repetitive (two impacts within 24) moderate skull impact to adult mice observed no significant changes in DTI measurements compared to controls (9). Significant decrease in axial diffusivity was registered after seven days following trauma. These experimental studies suggest that at least in moderate to severe head trauma animal models DTI may be a reliable marker for identifying early axonal injury and disconnection.

The second clinically relevant question is, given the early occurrence of axonal injury even in mild TBI, is there a therapeutic window for the use of drugs to ameliorate axonal swelling and disconnections? Several studies have shown that targeting mitochondria damage and preserving cellular energy homeostasis by cyclosporin A (CsA), a potent inhibitor of $\mathrm{Ca2+-induced} \mathrm{mitochondrial} \mathrm{damage,}$ administered intrathecally 30 min prior to traumatic brain injury, preserved mitochondrial integrity, significantly reduced spectrin proteolysis and neurofilament compaction and attenuated axonal degeneration. (15, 59, 60, 73). These studies demonstrate the therapeutic potential of CsA administration in the early posttraumatic period to protect axonal disconnection. Similar to antiexcitotoxic therapy, further studies will be needed to identify the precise molecular mechanisms of axonal injury as well as their therapeutic targets.

\section{Antiapoptotic therapies}

The significant increase in apoptotic cell death in infant mice as revealed by caspase- 3 activation and our ultrastructural analysis supports previous findings that apoptosis is a major contributor to early post-traumatic neuronal degeneration in the immature brain compared to the more limited, biphasic and delayed apoptotic death in adults $(18,83,84)$. Apoptotic cell death and excitotoxicity similarly play crucial roles in the pathogenesis of TBI in the neonate $(70,85)$. In the clinic this phenomenon can potentially contribute to the unfavorable developmental outcomes reported in young children but at the same time be considered as a potential treatment window 
for targeted pharmacological treatment aimed at blocking mechanisms of apoptotic cell death such as free radical scavengers, antioxidants, the TNF inhibitor pentoxifylline and others $(64,85)$. Targeting the downstream effectors of neuronal apoptosis $(17,38)$ in the acute phase post trauma may have good therapeutic potential in the immature brain by allowing neurons and perhaps other cell types enough time to upregulate homeostatic protection systems. On the other hand, preventive measures to ameliorate progressive axonal injury and axotomyinduced deafferentiation, as discussed above, might be equally beneficial in preventing apoptotic cell death (see FelderhofMueser and Ikonomidou, 2000, for an extensive review) (29). Although there are several encouraging studies in the beneficial effect of hypothermia on apoptosis both experimentally and clinically $(4,46,76,77,79)$ further research initiatives must evaluate mechanisms of hypothermia induced post TBI-induced amelioration of apoptosis in the infant brain.

\section{CONCLUDING REMARKS}

At the time this manuscript was in preparation Rivara et al., 2019 (69) published an important report produced by 11 experts in the field of sport related concussions in children. The panel concluded that "....There is no clear evidence in the literature that a specific age or developmental stage in children is safer or more appropriate for starting contact sports..." and that "...Experiencing multiple concussions in youth is one risk factor among many that may be associated with more long-lasting symptoms and longer recovery." The consensus statement further elaborated on the limitations of both in the quantity and quality of evidence preventing experts to issue recommendations to parents and other stake holder for practicing in contact sports such as ice hockey and football and stated that still there is not enough good quality research "to help guide us for making recommendations for families about many things about concussions.".

It is upon the scientific and clinical communities to continue the development of state-of-the-art research on the mechanics, mechanism, diagnosis of infant and child TBIs of all severity grades, better practical treatment options in the clinic as well as promote studies on mechanisms of prevention and safety.

\section{CONFLICT OF INTEREST}

None.

\section{ACKNOWLEDGEMENTS}

I would like to express my deepest gratitude to my colleagues and co-authors with whom I worked with on TBI projects - Dr.
Olney’s group, Dr. Ikonomidou's group, Dr. Brody’s group, Dr. Bayly's group and finally Dr. Alexander Parsadanian, for their leadership and major contributions in exploring various aspects of the infant rodent trauma model.

\section{REFERENCES}

1. Adelson PD, Robichaud P, Hamilton RL, Kochanek PM. A model of diffuse traumatic brain injury in the immature rat. J Neurosurg 1996; 85:877-884. DOI: 10.3171/ jns.1996.85.5.0877.

2. Adelson PD, Dixon CE, Robichaud P, Kochanek PM. Motor and cognitive deficits following diffuse traumatic brain injury in the immature rat. J Neurotrauma 1997; 14:99-108. DOI: 10.1089/neu.1997.14.99.

3. Adelson P, Kochanek P. Head injury in children. J Child Neurol 1998; 13:2-15. DOI: 10.1177/088307389801300102.

4. Adelson D, Wisniewski S, Beca J, Brown D, Bell M, Muizelaar P, Okada P, Beers S, Balasubramani G, Hirtz D. Comparison of hypothermia and normothermia after severe traumatic brain injury in children (Cool Kids): a phase 3, randomised controlled trial. Lancet 2013; 12: 546-552. DOI: 10.1016/S1474-4422(13)70077-2.

5. Bailey CD, Johnson GV. Developmental regulation of tissue transglutaminase in the mouse forebrain. $J$ Neurochem 2004; 91(6):1369-79. DOI: 10.1111/j.14714159.2004.02825.x

6. Bayly P, Dikranian K, Black E, Young C, Qin Y, Labruyere J, Olney JW. Spatiotemporal evolution of apoptotic neurodegeneration following traumatic injury to the developing rat brain. Brain Res 2006; 1107(1): 70-81. DOI: 10.1016/j.brainres.2006.05.102

7. Bayly PV, Black EE, Pedersen RC, Leister EP, Genin GM. In vivo imaging of deformation and strain in an animal model of traumatic brain injury. J Biomechem 2006; 39(6):1086-95. DOI: 10.1016/j.jbiomech.2005.02.014

8. Benesova, O. Brain maldevelopment and delayed neurobehavioral deviations, induced by perinatal insults, and possibilities of their prevention. J Hyg Epidemiol Microbiol Immunol. 1983; 27(4):373-380. PMID: 6663069.

9. Bennett R, Mac Donald Ch., Brody D. Diffusion Tensor Imaging Detects Axonal Injury in a Mouse Model of Repetitive Closed-Skull Traumatic Brain Injury. Neurosci Lett 2012; 513(2): 160-165. DOI: 10.1016/j. neulet.2012.02.024.

10. Bernal J, Nunez J. Thyroid hormone action, and brain development. Trends Endocrinol Metab 2000; 133:390398. DOI: 10.1530/eje.0.1330390

Biomed Rev 30, 2019 
11. Bittigau P, Pohl D, Sifringer M, Shimizu H, Ikeda M, Stadthaus D, et al. Modeling pediatric head trauma: mechanisms of degeneration and potential strategies for neuroprotection. Restor Neurol Neurosci 1998; 13:11-23. PMID: 12671284.

12. Bittigau $P$, Sifringer M, Pohl D, Stadthaus D, Ishimaru $\mathrm{M}$, Shimizu $\mathrm{H}$, et al. Apoptotic neurodegeneration following trauma is markedly enhanced in the immature brain. Ann Neurol 1999; 45:724-735. DOI: $10.1002 / 1531-8249(199906) 45: 6<724:: a i d-$ ana6>3.0.co;2-p.

13. Bittigau P, Sifringer M, Felderhoff-Mueser U, Hansen HH, Ikonomidou C. Neuropathological and biochemical features of traumatic injury in the developing brain. Neurotox Res 2003; 5(7):475-90. DOI: 10.1007/bf03033158.

14. Bittigau P, Sifringer M, Felderhoff-Mueser U, Ikonomidou Ch. Apoptotic neurodegeneration in the context of traumatic injury to the developing brain. Exp Tox Pathol 2004; 56:83-89. DOI: 10.1016/j.etp.2004.04.006.

15. Büki A, Okonkwo D, Povlishock J. Postinjury cyclosporin A administration limits axonal damage and disconnection in traumatic brain injury. J Neurotrauma 1999; 16 (6):51121. DOI: 10.1089/neu.1999.16.511.

16. Calderó J, Prevette D, Mei X, Oakley RA, Li L, Milligan $\mathrm{C}$, et al. Peripheral target regulation of the development and survival of spinal sensory and motor neurons in the chick embryo. J Neurosci. 1998; 18(1):356-70. DOI: 10.1523/JNEUROSCI.18-01-00356.1998.

17. Cheng Y, Deshmukh M, D’Costa A, Demaro J, Gidday JM, Shah A, et al. Caspase inhibitor affords neuroprotection with delayed administration in a rat model of neonatal hypoxic-ischemic brain injury. J Clin Invest 1998; 9:19921999. DOI: $10.1172 / J C I 2169$.

18. Conti AC, Raghupathi R, Trojanowski JQ, McIntosh TK. Experimental brain injury induces regionally distinct apoptosis during the acute and delayed post-traumatic period. J Neurosci 1998; 18:5663-5672. DOI: 10.1523/ JNEUROSCI.18-15-05663.1998.

19. Coulter I. Forsyth R. Pediatric traumatic injury. Curr Opin Pediatr 2019; 31:1040-8703. DOI:10.1097/ MOP.0000000000000820.

20. Dikranian K, Cohen R, Mac Donald Ch, Pan Y, Brakefield D, Bayly P, Parsadanian A. Mild traumatic brain injury to the infant mouse causes robust white matter axonal degeneration which precedes apoptotic death of cortical and thalamic neurons. Exp Neurol 2008; 211(2): 551-560.
DOI: 10.1016/j.expneurol.2008.03.012

21. Dixon CE, Clifton GL, Lighthall JW, Yaghmai A, Hayes RL. A controlled cortical impact model of traumatic brain injury in the rat. J Neurosci Methods 1991; 39:253-262. DOI: 10.1016/0165-0270(91)90104-8.

22. Dobbing J, Sands J. Quantitative growth and development of human brain. Arch Dis Child 1973; 48:757-767. DOI: 10.1136/adc.48.10.757. DOI: 10.1136/adc.48.10.757.

23. Dobbing J, Sands J. Comparative aspects of the brain growth spurt. Early Hum Dev 1979; 3:79-83. DOI: 10.1016/0378-3782(79)90022-7.

24. Dutschke J, Finnie J, Manavis, Anderson R. Semiquantitation of Axonal Injury in Traumatically Damaged Brains Using Color Deconvolution, Appl Immunohistochem Mol Morphol 2017; 25:277-281. DOI: 10.1097/PAI.0000000000000273

25. Ewing-Cobbs L, Prasad M, Kramer L, Louis PT, Baumgartner J, Fletcher JM, et al. Acute neuroradiologic findings in young children with inflicted or noninflicted traumatic brain injury. Childs Nerv Syst 2000; 16:25-33. DOI: $10.1007 / \mathrm{s} 003810050006$

26. Farkas O, Povlishock J. Cellular and subcellular change evoked by diffuse traumatic brain injury: a complex web of change extending far beyond focal damage. Prog Brain Res 2007; 161:43-59. DOI: 10.1016/S00796123(06)61004-2

27. Faden A, Demediuk P, Panter SS, Vink R. The role of excitatory amino acids and NMDA receptors in traumatic brain injury. Science 1989; 44:798-800. DOI: 10.1126/ science. 2567056

28. Feng G, Mellor R, Bernstein M, Keller-Peck C, Nguyen Q, Wallace $\mathrm{M}$, et al. Imaging neuronal subsets in transgenic mice expressing multiple spectral variants of GFP. Neuron 2000; 28:41-51. DOI: 10.1016/s0896-6273(00)00084-2

29. Felderhoff-Mueser U, Ikonomidou, Ch. Mechanisms of neurodegeneration after pediatric brain injury. Curr Opin Neurol 2000; 13 (2):141-145. DOI: 10.1097/00019052200004000-00005.

30. Feeney D, Boyeson M, Linn R, Murray H, Dail W. Responses to cortical injury. I. Methodology and local effects of contusions in the rat. Brain Res 1981; 211:6777. DOI: 10.1016/0006-8993(81)90067-6

31. Geddes J, Hackshow, G. Vowles, Nickols C., Whitwell H. Neuropathology of inflicted injury in children. I. Patterns of brain damage. Brain 2001; 124:1290-1298. DOI: 10.1093/brain/124.7.1290 
32. Geddes J, Hackshow, G. Vowles, C. Nickols, H. Whitwell, Neuropathology of inflicted injury in children. II. Microscopic brain injury in infants. Brain 2001; 124:12991306. DOI: 10.1093/brain/124.7.1299

33. Gentleman S, Nash MJ, Sweeting CJ, Graham DI, Roberts G. Beta-amyloid precursor protein (beta APP) as a marker for axonal injury after head injury. Neurosci Lett 1993; 160 (2):139-44. DOI: 10.1016/03043940(93)90398-5.

34. Girard T, Thomas J, Garrison M, Ehlers C, Riley E. Nicotine exposure during the neonatal growth spurt produces hyperreactivity in preweanling rats. Neurotoxicol Teratol 2000; 22(5):695-701. DOI: 10.1016/ s0892-0362(00)00096-9.

35. Gleckman AM, Bell MD, Evans RJ, Smith TW. Diffuse axonal injury in infants with nonaccidental craniocerebral trauma: enhanced detection by betaamyloid precursor protein immunohistochemical staining. Arch Pathol Lab Med 1999; 123:146-151. DOI: 10.1043/0003-9985(1999)123<0146:DAIIIW>2 .0.CO;2.

36. Gremelt A, Braun U. Analgesia and sedation in patients with head trauma. Anaesthesist, 1995; 44:559-565. PMID: 8592967.

37. Gunitz G. Early management of head-brain trauma patients. Anaesthesist 1995; 44:369-391. DOI: 10.1007/ s001010050166.

38. Han B, Holtzman DB. BDNF protects the neonatal brain from hypoxic-ischemic injury in vivo via the ERK pathway. J Neurosci 2000; 20:5775-5781. DOI: 10.1523/ JNEUROSCI.20-15-05775.2000.

39. Helland I, Smith L, Saarem K, Saugstad OD, Drevon Ch. Maternal supplementation with very-long-chain n-3 fatty acids during pregnancy and lactation augments children's IQ at 4 years of age. Pediatrics 2003; 111(1):39-44. DOI: 10.1542/peds.111.1.e39.

40. Huh J, Widing A, Raghupathi R. Midline brain injury in the immature rat induces sustained cognitive deficits, bihemispheric axonal injury and neurodegeneration. Experimental Neurology 2008; 213:84-92. DOI: 10.1016/j.expneurol.2008.05.009.

41. Ikonomidou C, Qin Y, Labruyere J, Kirby C, Olney J. Prevention of trauma-induced neurodegeneration in infant rat brain. Pediatr Res 1996; 39(6):1020-1027. DOI: 10.1203/00006450-199606000-00015.

42. Ishimaru MJ, Ikonomidou C, Tenkova TI, Der TC,
Dikranian K, Sesma MA, Olney JW. Distinguishing excitotoxic from apoptotic neurodegeneration in the developing rat brain. J Comp Neurol 1999; 408:461-476. PMID: 10340498.

43. Johnson V, Meaney D, Cullen K, Smith D. Animal models of traumatic brain injury. Grafman and Salazar, Editors. Handbook of Clinical Neurology, Vol. 127 (3rd series) Traumatic Brain Injury, Part I, Ch. 8, 2015. DOI:10.1016/ B978-0-444-52892-6.00008-8

44. Kelley B, Farkas O, Lifshitz J, Povlishock J. Traumatic axonal injury in the perisomatic domain triggers ultrarapid secondary axotomy and Wallerian degeneration. Exp Neurol 2006; 198(2):350-360. DOI: 10.1016/j. expneurol.2005.12.017.

45. Kempe CH, Silverman FN, Steele BF, et al. The battered child syndrome. JAMA1962; 181:17-24. DOI: 10.1001/ jama.1962.03050270019004.

46. Kochanek P, Bell M. Tackling the challenges of clinical trials for severe traumatic brain injury in children: Screening, phenotyping, and adapting. Critical Care Medicine 2015; 45(7):1544-1546. DOI: 10.1097/ CCM.0000000000001041.

47. Kolb B, Whishaw IQ. An introduction to brain and behavior. New York: Worth Publishers, 2001.

48. Koskiniemi M, Kykka T, Nybo T, Jarho L. Long-term outcome after severe brain injury in pre-schoolers is worse than expected. Arch Pediatr Adolesc Med 1995; 49:249254. DOI: 10.1001/archpedi.1995.02170150029004.

49. Kretschmann H, Kammradt G, Krauthausen I, Sauer B, Wingert F. Brain growth in man. Bibl Anat 1986; 28:1-26. PMID: 3707509.

50. Levchakov A, Linder-Ganz E, Raghupathi R, Margulies $\mathrm{S}$, Gefen A. Computational studies of strain exposures in neonate and mature rat brains during closed head impact. J Neurotrauma. 2006; O23(10):1570-1580. DOI: 10.1089/ neu.2006.23.1570.

51. Mac Donald Ch, Dikranian K, Bayly Ph, Holtzman D, Brody D. Diffusion tensor imaging reliably detects experimental traumatic axonal injury and indicates approximate time of injury. J Neurosci 2007; 27(44):11869 -11876. DOI: 10.1523/JNEUROSCI.3647-07.2007

52. Мac Donald Ch, Dikranian K, Song SK, Bayly PV, Holtzman DM, Brody D. Detection of traumatic axonal injury with diffusion tensor imaging in a mouse model of traumatic brain injury. Exp Neurol 2007; 205(1):116-131. DOI: 10.1016/j.expneurol.2007.01.035 
53. Mahoney W, D’Souza B, Haller A, Rogers M, Epstein M, Freeman J. Long-term outcome of children with severe head trauma and prolonged coma. Pediatrics 1983; 71:756-762. PMID: 6835758.

54. Markou K, Georgopolous N, Kyriazopoulou V, Vagenakis GA. Iodine induced hypothyroidism. Thyroid 2001; 11:501-507. DOI: 10.1089/105072501300176462.

55. Marmarou A, Foda MA, van den Brink W, Campbell J, Kita H, Demetriadou K. A new model of diffuse brain injury in rats. Part I: Pathophysiology and biomechanics. J Neurosurg 1994; 80:291-300. DOI: 10.3171/jns.1994.80.2.0291.

56. McIntosh TK, Vink R, Noble L, Yamakami I, Fernyak S, Faden AI. Traumatic brain injury in the rat: characterization of a lateral fluid-percussion model. Neuroscience 1989; 28:233-244. DOI: 10.1016/0306-4522(89)90247-9.

57. Maroles M. Vester R. Bilo A, Loeve R, Van Zandwijk J. Modeling of inflicted head injury by shaking trauma in children: what can we learn? Part I: A systematic review of animal models Forensic Science, Medicine and Pathology 2019; 15:408-422. DOI: 10.1007/s12024-019-0082-3.

58. Natale J, Cheng Y, Martin L. Thalamic neuron apoptosis emerges rapidly after cortical damage in immature mice. Neuroscience 2002; 112:665-676. DOI: 10.1016/s03064522(02)00098-2.

59. Okonkwo D, Povlishock T. An intrathecal bolus of cyclosporin A before injury preserves mitochondrial integrity and attenuates axonal disruption in traumatic brain injury. J Cereb Blood Flow Metab 1999; 19:443-451. DOI: 10.1097/00004647-199904000-00010.

60. Okonkwo D, Buki A, Siman R, Povlishock T. Cyclosporin A limits calcium-induced axonal damage following traumatic brain injury. Neuroreport 1999; 10:353-358. DOI: 10.1097/00001756-199902050-00026.

61. Paul A, Adamo M. Non-accidental trauma in pediatric patients: a review of epidemiology, pathophysiology, diagnosis and treatment. Transl Pediatr 2014; 3(3):195207. DOI: 10.3978/j.issn.2224-4336.2014.06.01.

62. Price JL. Thalamus. Paxinos, G. Editor. In: The Rat Nervous System. London, Acad Press, 1995.

63. Prins ML, Lee SM, Cheng CL, Becker DP, Hovda DA. Fluid percussion brain injury in the developing and adult rat: a comparative study of mortality, morphology, intracranial pressure and mean arterial blood pressure. Dev Brain Res 1996; 95:272-282. DOI: 10.1016/01653806(96)00098-3.
64. Pohl D, Bittigau P, Ishimaru M, Stadthaus D, Hubner C, Olney JW, Turski L, Ikonomidou C. N-methyl-D-aspartate antagonists and apoptotic cell death triggered by head trauma in developing rat brain. Proc Natl Acad Sci 1999; 96:2508-2513. DOI: 10.1073/pnas.96.5.2508.

65. Pullela R, Raber J, Pfankuch T, Ferriero D, Claus C, Koh E, Yamauchi T, Rola R, Fike J, Noble-Haeusslein L. Traumatic injury to the immature brain results in progressive neuronal loss, hyperactivity and delayed cognitive impairments. Dev Neurosci 2006; 28(4-5):396409. DOI: 10.1159/000094166.

66. Rice D, Barone S Jr. Critical periods of vulnerability for the developing nervous system: evidence from humans and animal models. Environ Health Perspect 2000; 108 (Suppl 3):511-533.. DOI: 10.1289/ehp.00108s3511.

67. Raghupathi R, Margulies S. Traumatic axonal injury after closed head injury in the neonatal pig. J Neurotrauma.2002; 19(7):843-53. DOI: 10.1089/08977150260190438.

68. Reeves TM, Phillips LL, Povlishock JT. Myelinated and unmyelinated axons of the corpus callosum differ in vulnerability and functional recovery following traumatic brain injury. Exp Neurol 2005; 196 (1):126-137. DOI: 10.1016/j.expneurol.2005.07.014.

69. Rivara F, Tennyson, R Mills B, Browd S, Emery C, Gioia G, Giza Ch, Herring S, Janz K, LaBella C, Valovich MT, Meehan Wi, Patricios J. Consensus statement on sportsrelated concussions in youth sports using a modified Delphi approach. JAMA Pediatrics 2019; E1-E7. DOI: 10.1001/jamapediatrics.2019.4006.

70. Ruppel R, Kochanek P, Adelson P, Rose E, Wisniewski R, Bel J, Clark S, Marion D, Graham H. Excitatory amino acid concentrations in ventricular cerebrospinal fluid after severe traumatic brain injury in infants and children: the role of child abuse. J Pediatr 2001; 138:18-25. DOI: 10.1067/mpd.2001.110979.

71. Salmaso N, Jablonska B, Scafidi J, Vaccarino F, Gallo V. Neurobiology of premature brain injury. Nat Neurosci 2014; 17(3):341-346. DOI:10.1038/nn.3604.

72. Shibata $\mathrm{H}$. Efferent projections from the anterior thalamic nuclei to the cingulate cortex in the rat. J Comp Neurol 1993; 330:533-542. DOI: 10.1002/cne.903300409.

73. Singleton R, Stone J, Okonkwo D, Pellicane A, Povlishock J. The immunophilin ligand FK506 attenuates axonal injury in an impact-acceleration model of traumatic brain injury. J Neurotrauma 2001; 18(6):607-614. DOI: 10.1089/089771501750291846. 
74. Stein D, Geddes S, Sribnick E. Recent developments in clinical trials for the treatment of traumatic brain injury. Grafman and Salazar, Editors. Handbook of Clinical Neurology, Vol. 127 (3rd series) Traumatic Brain Injury, Part I J. Elsevier B.V. 2015. DOI: 10.1016/B978-0-44452892-6.00028-3.

75. Stein SC, Spettell CM. Delayed and progressive brain injury in children and adolescents with head trauma. Pediatr Neurosurg 1995; 23:299-304. DOI: 10.1159/000120975.

76. Su E, Bell MJ, Wisniewski SR, Adelson PD, JaneskoFeldman KL, Salonia R, et al. $\alpha$-Synuclein levels are elevated in cerebrospinal fluid following traumatic brain injury in infants and children: the effect of therapeutic hypothermia. Dev Neurosci 2010; 32(5-6):385-95. DOI: 10.1159/000321342

77. Thabet F, Tabarki B. Therapeutic hypothermia in children: Which indications remain in 2018? Archives de Pediatrie 2019; 26: 308-311. DOI: 10.1016/j.arcped.2019.05.010.

78. Tolias C, Bullock M. Critical appraisal of neuroprotection trials in head injury: What have we learned? NeuroRx 2004; 1:71-79. DOI: 10.1602/neurorx.1.1.71.

79. Wang Ch, Zhao C, He Y, Li L, W, Huang Z, Deng Y, Li W. Mild hypothermia reduces endoplasmic reticulum stress induced apoptosis and improves neuronal functions after severe traumatic brain injury. Brain Behav 2019 (in press). DOI: 10.1002/brb3.1248
80. Wozniak J, Krach L, Warda E, Mueller B, Muetzel R, Schnoebelen S, Kiraguc A, Lim K, Neurocognitive and neuroimaging correlates of pediatric traumatic brain injury: A diffusion tensor imaging (DTI) study. Arch Clin Neuropsychol 2007; 22(5): 555-568. DOI: 10.1016/j. acn.2007.03.004.

81. Xiang H, Girard T, Ward GR, Nguyen H, Wainwright PE. Exposure to ethanol and nicotine during the brain growth spurt: spatial DMP performance in male rats. Pharmacol Biochem Behav 2001; 68(3):515-23. DOI: 10.1016/s00913057(01)00452-x.

82. Yager J, Thornhill J. The effect of age on susceptibility to hypoxic-ischemic brain damage. Neurosci Biobehav Rev 1997; 21(2):167-74. DOI: 10.1016/s01497634(96)00006-1.

83. Yakovlev A, Knoblach S, Fan L, Fox G, Goodnight R, Faden A. Activation of CPP32-like caspases contributes to neuronal apoptosis and neurological dysfunction after traumatic brain injury. J Neurosci 1997; 17:7415-7424. DOI: 10.1523/JNEUROSCI.17-19-07415.1997.

84. Yakovlev A, Faden A. Caspase-dependent apoptotic pathways in CNS injury. Mol Neurobiol 2001; 24(13):131-44. DOI: 10.1385/MN:24:1-3:131.

85. Zhang X., Chen Y, Jenkins L, Kochanek P, Clark R. Bench-to-bedside review: Apoptosis/programmed cell death triggered by traumatic brain injury. Crit Care 2005; 9:66-75. DOI:10.1186/cc2950 